Case Report

\title{
Unusual Extramedullary Plasmacytoma: A Rare but Possible Cause of Lymphadenopathy in Chronic Lymphocytic Leukemia
}

\author{
S. P. Chantepie, ${ }^{1}$ Q. Cabrera, ${ }^{1}$ J. B. Mear, ${ }^{1}$ V. Salaun, ${ }^{2}$ E. Lechapt-Zalcman, ${ }^{3}$ and M. Macro ${ }^{1}$ \\ ${ }^{1}$ Department of Hematology, Caen University Hospital, 14000 Caen, France \\ ${ }^{2}$ Hematology Laboratory, Caen University Hospital, 14000 Caen, France \\ ${ }^{3}$ Department of Pathology, Caen University Hospital, 14000 Caen, France
}

Correspondence should be addressed to S. P. Chantepie; chantepie-s@chu-caen.fr

Received 28 May 2015; Revised 17 June 2015; Accepted 24 June 2015

Academic Editor: Thomas R. Chauncey

Copyright (C) 2015 S. P. Chantepie et al. This is an open access article distributed under the Creative Commons Attribution License, which permits unrestricted use, distribution, and reproduction in any medium, provided the original work is properly cited.

\begin{abstract}
Cervical bilateral lymphadenopathy is a frequent event during chronic lymphocytic leukemia (CLL) natural history. However, lymph node biopsy is generally not required as long as transformation into an aggressive lymphoma (Richter syndrome) is not suspected. We present here a rare case of CLL patient who developed progressive bilateral cervical lymph node and bilateral tonsillar hypertrophy. CLL front-line therapy was ineffective leading to adenectomy and diagnosis of concomitant extramedullary plasmacytoma. Radiotherapy did not result in the disappearance of lymphadenopathy. Adenectomy should be performed in CLL cases to avoid misdiagnosis.
\end{abstract}

\section{Introduction}

Cervical bilateral lymphadenopathy is a frequent event during chronic lymphocytic leukemia (CLL) natural history. CLL diagnosis criteria include immunophenotype of the neoplastic lymphocytes to detect the coexpression of CD5 and Bcell surface antigens CD19, CD20, and CD23 on lymphocyte. However, lymph node biopsy is generally not required as long as transformation into an aggressive lymphoma (Richter syndrome) is not suspected. We present here a rare case of CLL patient who developed progressive bilateral cervical lymph node and bilateral tonsillar hypertrophy leading to diagnosis of concomitant extramedullary plasmacytoma. The clonal origin of the two diseases is also discussed.

\section{Case Presentation}

A 63-year-old patient with a history of CLL since 2003 was referred to the Caen University Hospital. Binet's stage was A, and Matutes score was 5. Immunophenotype revealed CD5/ CD19/kappa positive CLL cells. He complained of a gradual increase in bilateral cervical lymphadenopathy which measured $10 \mathrm{~cm}$ right and $5 \mathrm{~cm}$ left with bilateral tonsillar hypertrophy. He did not mention weight loss or night sweat. He also had lymphocytosis $(8.5 \mathrm{G} / \mathrm{L})$ and an IgG kappa monoclonal protein $(24 \mathrm{~g} / \mathrm{L})$. Fludarabine, cyclophosphamide, and rituximab therapy was started without any response on lymphadenopathy after 6 cycles. Four cycles of R-CHOP were also ineffective. Right cervical adenectomy and right tonsillectomy revealed extramedullary plasmacytoma with the same kappa light chain on histological examination (Figure 1) and in flow cytometry analysis compared to the initial circulating CLL clone. Flow cytometry plasma cells were CD38/CD138/CD56/kappa strong and negative for CD19/CD20/CD33/CD117/CD45. No CLL cells were found in nodes and tonsils. The bone marrow biopsy and bone marrow aspiration failed to detect any CLL residual disease or clonal plasma cells. PET-CT scan showed FDG uptake in the right and left cervical area, the base of the tongue, and the right tonsil (Figure 2(a)). Surprisingly, radiotherapy $40 \mathrm{~Gy}$ was ineffective (Figures 2(b) and 2(c)). Lymph nodes sizes eventually decreased with bortezomib and dexamethasone therapy leading to a very good partial response on monoclonal component and cervical plasmacytoma disappearance. The patient is still alive 3 years after treatment without any lymphadenopathy but with a low residual monoclonal component $(2 \mathrm{~g} / \mathrm{L})$. 


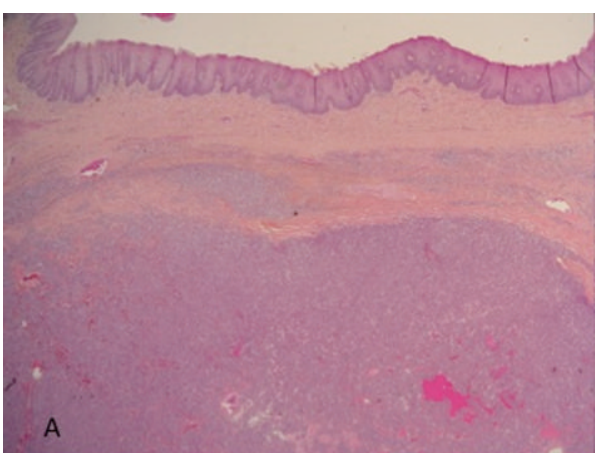

(a)

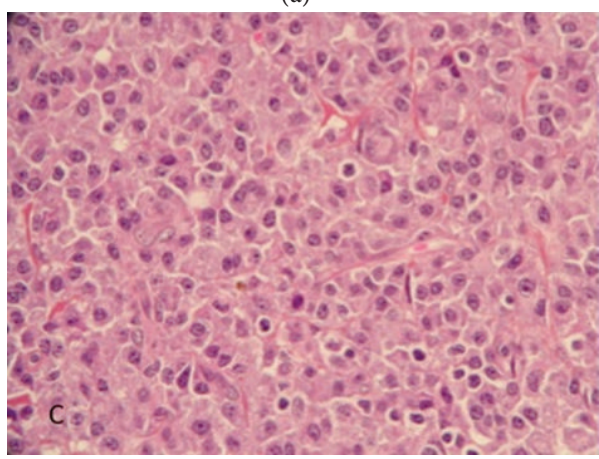

(c)

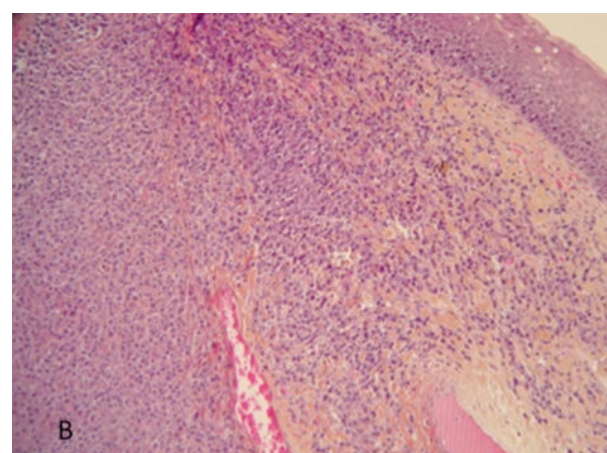

(b)

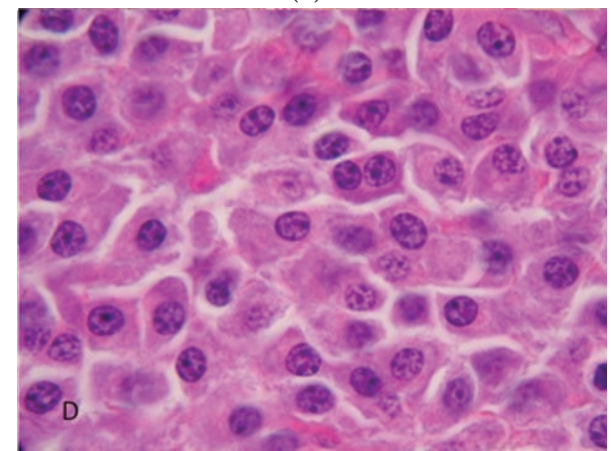

(d)

FIGURE 1: Tonsil biopsy section showing a diffuse and dense infiltrate of a plasma cell proliferation in the subepithelial tissue (hematoxylineosin-safran, original magnification $\times 2(a)$ and $\times 10$ (b)). The proliferation consists of mononuclear and multinucleated well-differentiated neoplastic plasma cells $(\times 40(\mathrm{c})$ and $\times 100(\mathrm{~d}))$.
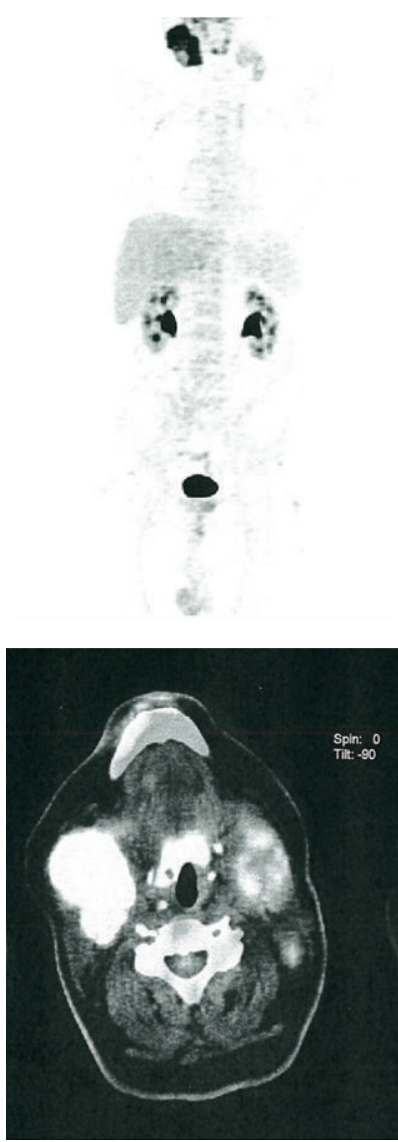

(a)
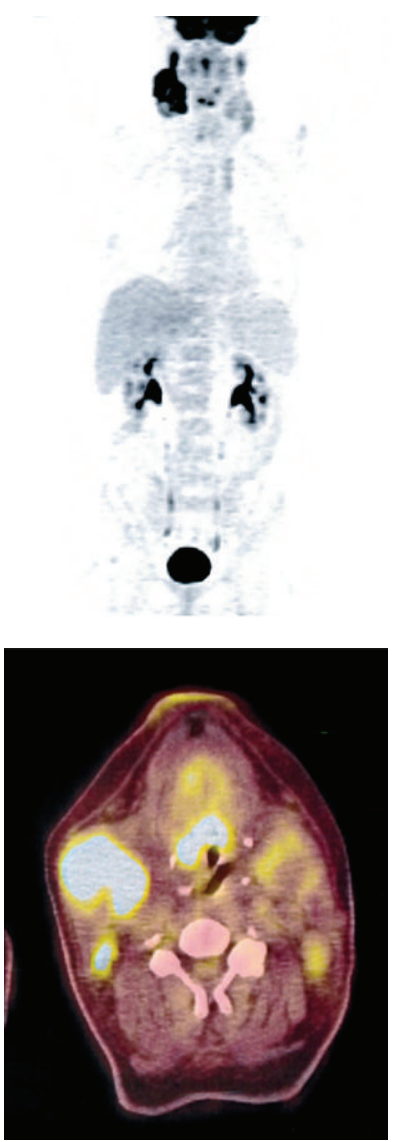

(b)
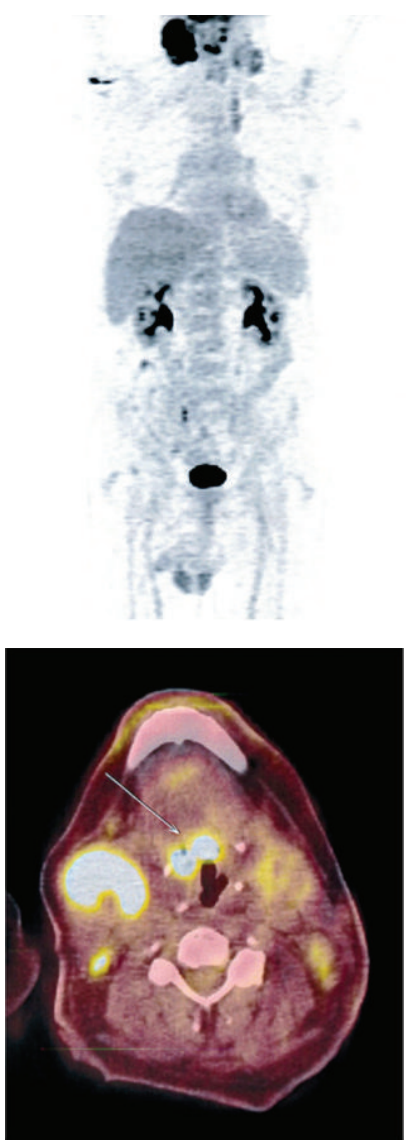

(c)

FIGURE 2: (a) PET-CT before radiotherapy showing bilateral abnormal uptake in cervical bilateral adenopathy and in right tonsil; (b) and (c) PET-CT 2 and 4 months after radiotherapy showing the persistence of FDG uptakes in the previous involved site. 


\section{Discussion}

To date, only 3 other cases of plasmacytoma in CLL patient have been described [1-3], but only one had the same light chain in plasmacytoma and CLL clone [1]. Other plasma cells disorders have been described in the context of CLL, as multiple myeloma or amyloidosis with or without the same light chain in both clones $[4,5]$. Several reports suggest that plasma cell clone may derive from CLL cells with the same immunoglobulin production [6]. Immunoglobulin gene rearrangement investigations support the theory of a single clone for two concomitant malignant diseases [7]. However, absence of clonal chromosomal or molecular relationship between concomitant B-CLL and multiple myeloma has been described $[8,9]$ and recent analysis with single nucleotide polymorphism (SNP) mapping array and FISH analyses on bone marrow (BM) smears supported the hypotheses of biclonal origin [10].

Whatever the clonal origin of the two diseases is, the "take home" message is to perform biopsy in patients with CLL when tumoral lymph nodes do not disappear with conventional therapy. Lymphadenopathy in CLL patient may also be a plasmacytoma.

\section{Conclusion}

Lymphadenopathy in a CLL patient may lead to adenectomy to be sure of CLL diagnosis to avoid misdiagnosis and wrong therapeutic strategy.

\section{Consent}

Written informed consent was obtained from the patient for publication of this case report and any accompanying images. A copy of the written consent is available for review.

\section{Conflict of Interests}

The authors declare no conflict of interests.

\section{References}

[1] A. Pines, I. Ben-Bassat, G. Selzer, and B. Ramot, "Transformation of chronic lymphocytic leukemia to plasmacytoma," Cancer, vol. 54, no. 9, pp. 1904-1907, 1984.

[2] N. Yahata, O. Iwase, H. Iwama et al., "Chronic lymphocytic leukemia complicated by plasmacytoma originating from different clones," Leukemia and Lymphoma, vol. 39, no. 1-2, pp. 203-207, 2000.

[3] I. Belinchón, J. M. Ramos, J. Onrubia, and M. J. Mayol, “Primary cutaneous plasmocytoma in a patient with chronic lymphatic leukemia," Journal of the American Academy of Dermatology, vol. 35, no. 5, pp. 777-778, 1996.

[4] C. L. Alley, E. Wang, C. H. Dunphy et al., "Diagnostic and clinical considerations in concomitant bone marrow involvement by plasma cell myeloma and chronic lymphocytic leukemia/ monoclonal B-cell lymphocytosis: a series of 15 cases and review of literature," Archives of Pathology and Laboratory Medicine, vol. 137, no. 4, pp. 503-517, 2013.
[5] J. C. Brouet, J. P. Fermand, G. Laurent et al., "The association of chronic lymphocytic leukaemia and multiple myeloma: A study of eleven patients," British Journal of Haematology, vol. 59, no. 1, pp. 55-66, 1985.

[6] J. P. Fermand, J. M. James, P. Herait, and J. C. Brouet, "Associated chronic lymphocytic leukemia and multiple myeloma: origin from a single clone," Blood, vol. 66, no. 2, pp. 291-293, 1985.

[7] D. L. Saltman, J. A. Ross, R. E. Banks, F. M. Ross, A. M. Ford, and M. J. Mackie, "Molecular evidence for a single clonal origin in biphenotypic concomitant chronic lymphocytic leukemia and multiple myeloma," Blood, vol. 74, no. 6, pp. 2062-2065, 1989.

[8] H. Kaufmann, J. Ackermann, T. Nösslinger et al., "Absence of clonal chromosomal relationship between concomitant BCLL and multiple myeloma-a report on two cases," Annals of Hematology, vol. 80, no. 8, pp. 474-478, 2001.

[9] H. Chang, A. Wechalekar, L. Li, and D. Reece, "Molecular cytogenetic abnormalities in patients with concurrent chronic lymphocytic leukemia and multiple myeloma shown by interphase fluorescence in situ hybridization: evidence of distinct clonal origin," Cancer Genetics and Cytogenetics, vol. 148, no. 1, pp. 4448, 2004

[10] M. Pantic, P. Schroettner, D. Pfeifer et al., "Biclonal origin prevails in concomitant chronic lymphocytic leukemia and multiple myeloma," Leukemia, vol. 24, no. 4, pp. 885-890, 2010. 


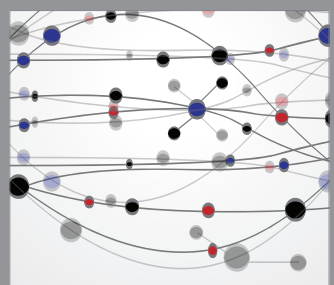

The Scientific World Journal
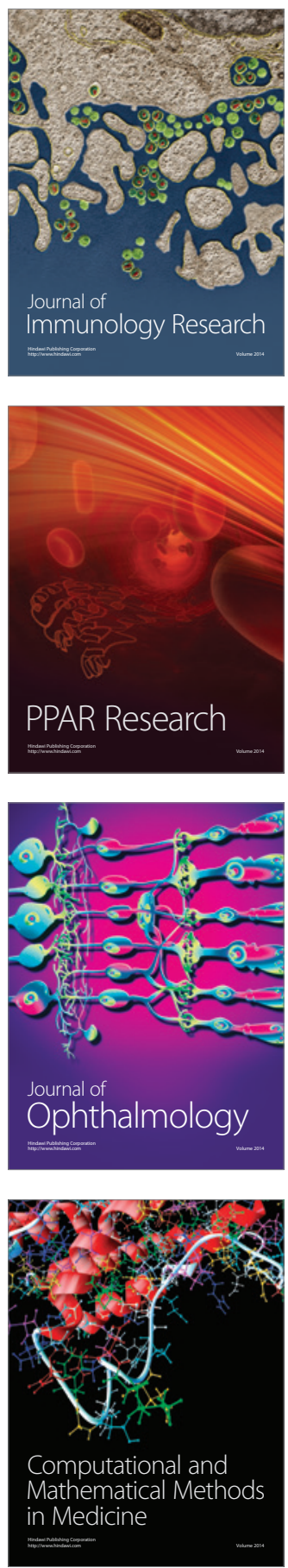

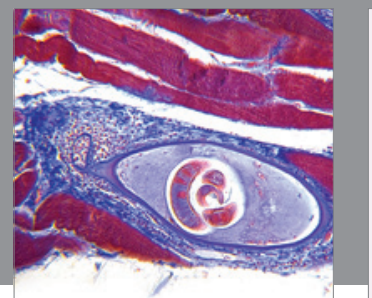

Gastroenterology

Research and Practice
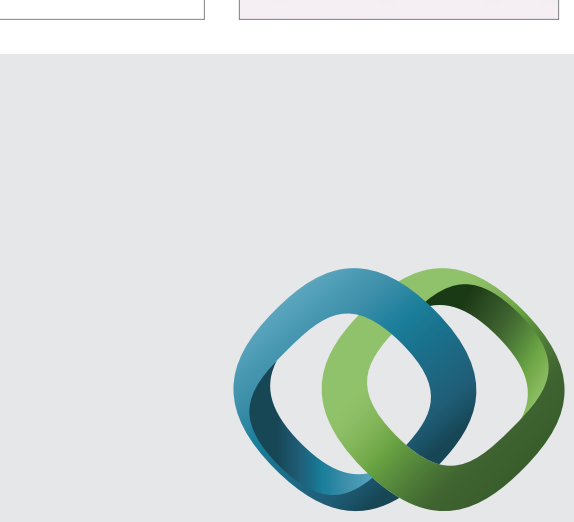

\section{Hindawi}

Submit your manuscripts at

http://www.hindawi.com
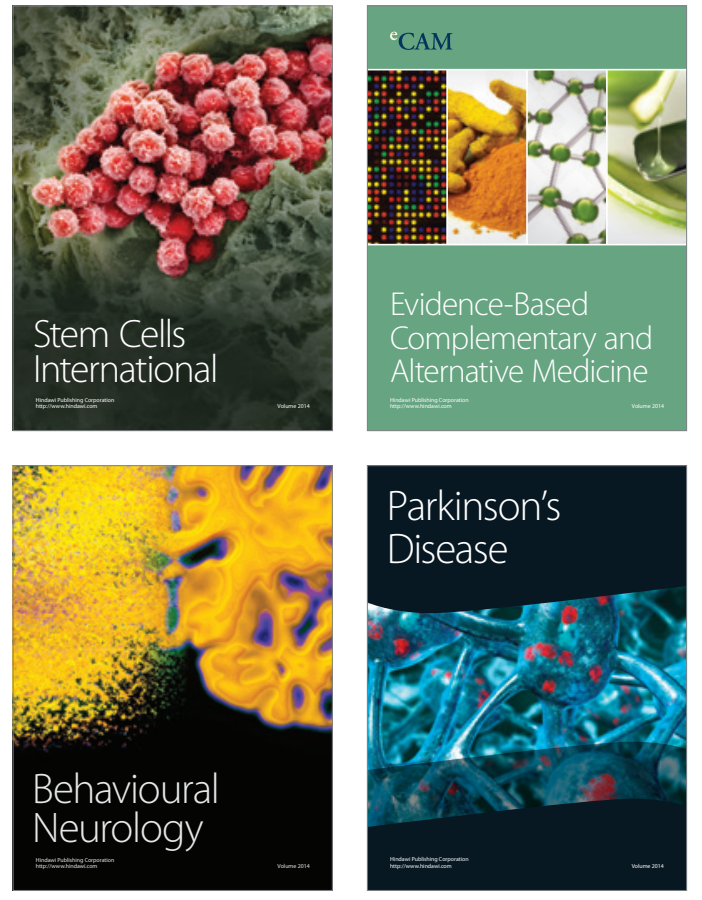
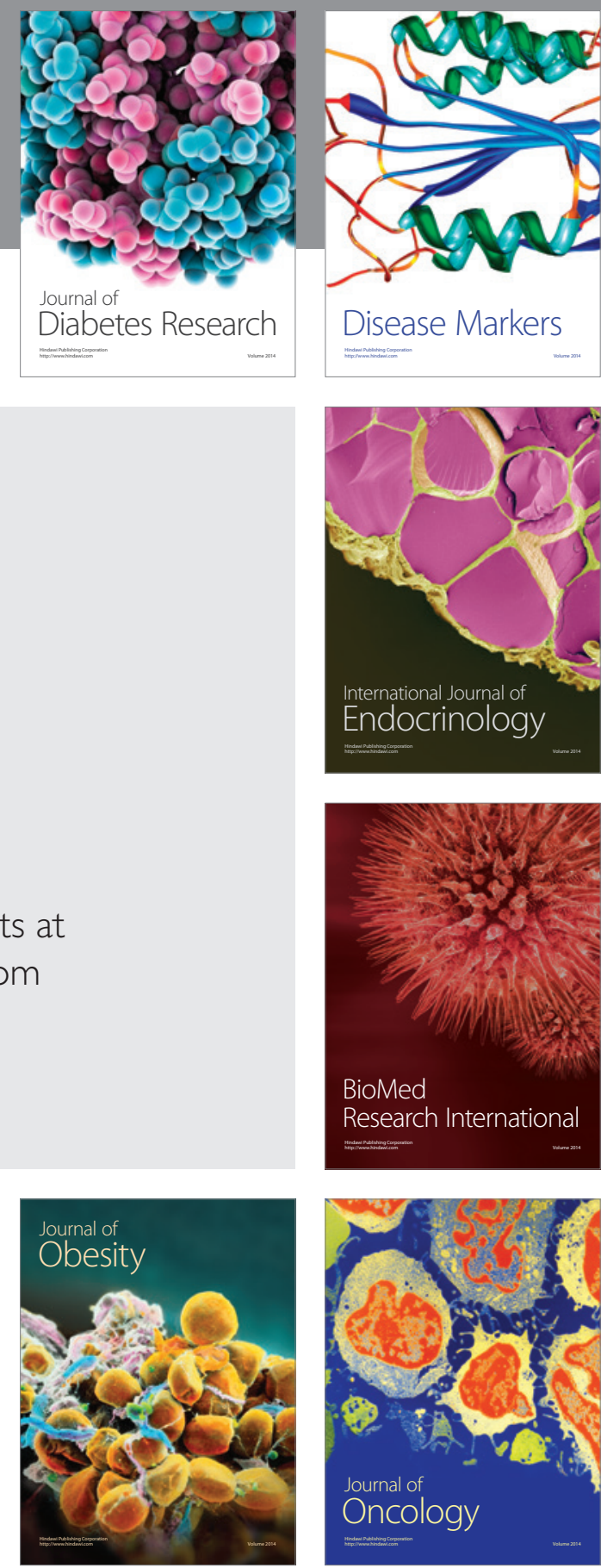

Disease Markers
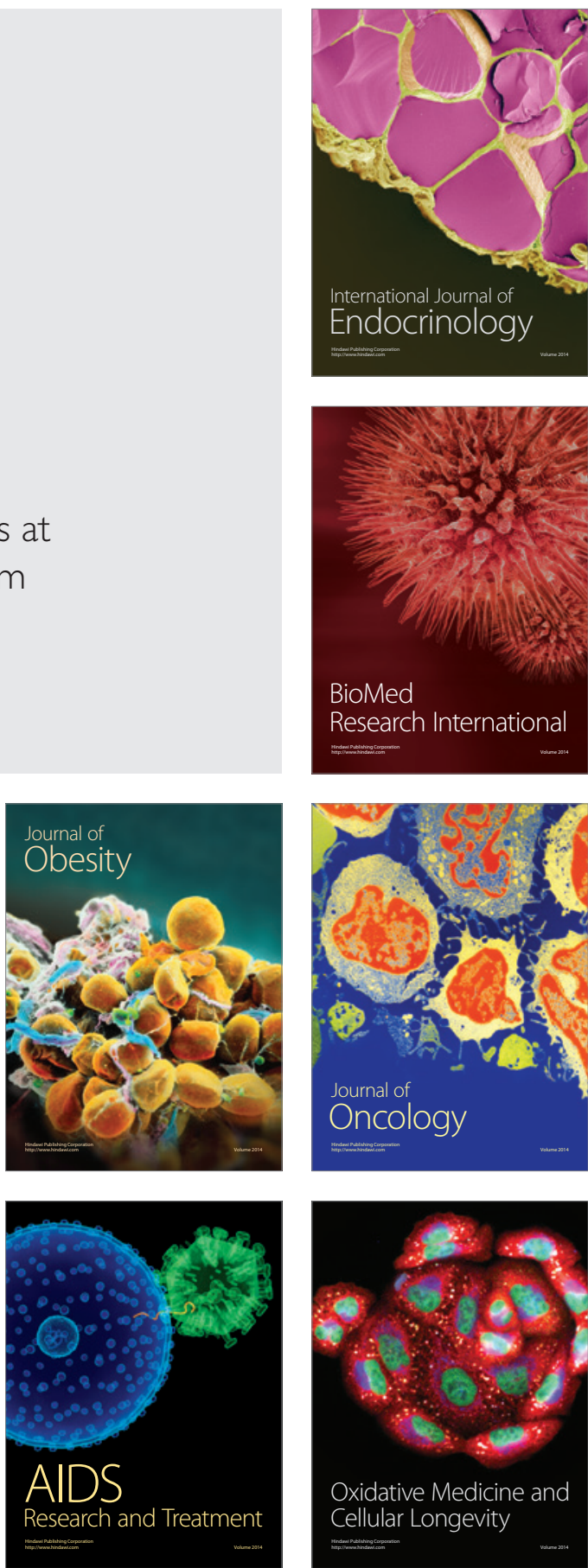